\title{
Increasing Critical Thinking in Web-Based Graduate Management Courses
}

\author{
Conna Condon \\ University of Liverpool, \\ Laureate Universities, \\ Torrance, CA, USA
}

\author{
Raul Valverde \\ Concordia University and \\ University of Liverpool, \\ Montreal, QC, Canada
}

\section{conna.condon@my.ohecampus.com}

\section{rvalverde@jmsb.concordia.ca}

\begin{abstract}
A common approach for demonstrating learning in online classrooms is through submittal of research essays of a discussion topic followed by classroom participation. Issues arose at an online campus of a university regarding the originality and quality of critical thinking in the original submittals. Achievement of new course objectives oriented to demonstrating synthesis and analysis were being impacted by questions which typically resulted in paraphrased reports from the course text, websites and articles. This research study posited that conscientiously revising the types of questions, developing writing skills within the course, and utilizing rubrics which rewarded original content (the guidelines) could increase the original content within submittals.

A mixed-methods approach was used. The experience of taking a combo Accounting/Operations Management Course for IT Majors was defined as the phenomenological case study. A section with the existing questions provided an 'as is' basis for content analysis. Changes to the course were developed by a panel of senior faculty and implemented in a pilot section of the course. The impact of the changes on the pilot section was measured using content analysis.
\end{abstract}

There were varied improvements in the pilot course. While all Discussion Question (DQs) had increased original content, they were not equally improved. Further analysis revealed that ongoing content analysis and writing skills training would continue to improve results.

Keywords: Critical Thinking, Discussion Questions, Online Learning, Graduate Online Management Education, Online MBA, Bloom Taxonomy in Management Courses, Delphi approach.

\section{Introduction}

Material published as part of this publication, either on-line or in print, is copyrighted by the Informing Science Institute.

Permission to make digital or paper copy of part or all of these works for personal or classroom use is granted without fee provided that the copies are not made or distributed for profit or commercial advantage AND that copies 1) bear this notice in full and 2) give the full citation on the first page. It is permissible to abstract these works so long as credit is given. To copy in all other cases or to republish or to post on a server or to redistribute to lists requires specific permission and payment of a fee. Contact Publisher@InformingScience.org to request redistribution permission.
In recent years online learning has become an accepted approach to earn a graduate degree in business. As a result many graduate business programs have emerged with different online teaching paradigms. Several UK schools, including Open University and University of Liverpool, represented at the $2013 \mathrm{Eu}$ ropean Distance Education Network (EDEN) Conference (www.eden.com), have offerings that are accredited and recognized as having the same rigor as 
traditional education. Each year more traditional universities are adding online programs using a variety of educational paradigms.

A United Kingdom based online graduate program (The University) uses weekly asynchronous discussions triggered by learner responses to discussion questions as one of their primary methods for online learning (Du, Yu, \& Olinzock, 2011). Discussions are used in every online course taught for the graduate business and information technology programs. Each week, the course faculty will assign Discussion Questions (DQs) from an available list of questions for that week. Students asynchronously post answers to these questions in a weekly discussion area of the online classroom by a stated 'due by' date. These posts are accessed by all the students taking the class to read and reply to as part of the participation requirements. The intent is for the students to demonstrate learning from both developing the original essays and by entering into an exchange of ideas asynchronously for the remainder of the week.

Students are graded for the initial answers to the Discussion Questions as well as separately for the quality of their participation in the discussion between students. Students must make a number of follow-on posts (the minimum number varies between programmes) and their comments must add positively and significantly to the classroom discussion (Choi, Land, \& Turgeon, 2007). However, some research studies have shown that students are not always effective at engaging in critical discussions (Levy \& Ellis, 2006; Strang, 2010). The authors particularly experienced this problem in an Accounting and Operations Management Course for Information System Management Majors. Additionally, because the students tended to answer the questions by reporting what the text or other authors said, the majority of the content was unoriginal and often also incorrectly cited.

The question was raised as to whether there was anything faculty could do in their courses to decrease the volume of unoriginal content and increase the portions of the original essays that reflected the students' own experience and illustrated their ability to think critically. During workshop discussions at an annual conference at the University of Liverpool, faculty identified several potential reasons that could explain the problems discussed. For instance, some students are admitted to graduate studies based on their previous professional experience or technical education but they might not have had any courses which developed English composition and critical thinking skills. Land (2000) found that enrolled students are often limited in prior subject matter coverage. Some students may have learned within their culture not to question authority, indeed, that repeating what an authority has said in their own words and without citation is honoring that authority.

An opportunity to research the issues arose when the UK University (The University) reviewed all courses to ensure that the course objectives implemented the use of the Bloom's Higher Order Thinking (Choi et al., 2007; Du et al., 2011; Ward, 2011). This happened as part of refining all Masters of Business and Masters of Information Systems by using verbs that are associated with Bloom's Level 4, 5 and 6 higher order thinking to optimally meet accreditation requirements. The new objectives required learners to demonstrate the ability to go beyond reporting what others have said (level 1,2 and 3) and rather analyze each of the elements identified in the course objectives and synthesize findings. In order to achieve the new objectives the discussion questions (DQs) needed to require the use of Bloom's level 4 through level 6 thinking. The researchers noted that the current questions did not require the students to exhibit analytical thinking. They further noted that the students were not currently demonstrating the thinking and writing skills to achieve the objectives.

Several faculty members reported that, in some courses, the discussion questions did not always align with the updated objectives. During preliminary research it was agreed that simply changing the questions would not necessarily result in responses which included analysis or synthesis. A 
research project was sponsored to enhance the achievement of learning objectives and critical thinking in online class forum asynchronous discussions. Prior research (Dennen \& Wieland, 2008; Guldberg \& Pilkington, 2006) has shown that the success in achieving learning outcomes is impacted by the type of discussion questions developed for a course. The researchers posited that the current questions did not require the students to exhibit analytical thinking. They further suggested that the students did not have the thinking and writing skills to achieve the objectives. The study therefore intended to answer the following research question: Can the DQ process from design through implementation and grading be improved to increase the achievement of learning objectives and critical thinking in online class forum asynchronous?

\section{Literature Review}

The importance of class discussion dates back as far as Kolb's study in 1984 (Andresen, 2009) when the process was identified as critically important to learning. The goal of the two weekly DQs and reply participation is to stimulate critical thinking and to demonstrate the achievement of learning objectives. According to Webb, Jones, Barker, and van Schaik (2004) student achievement of learning outcomes was significantly related to student participation in discussions via original discussion question submittals and replies. Higher levels of substantive participation correlated to higher grades on course exams.

\section{Critical Thinking}

Not all thinking is 'critical thinking.' A review of some university websites revealed different views amongst faculty as to their interpretation of a discussion question that requires critical thinking. A syllabus of the University of Dayton (2013) relates it to having a hypothesis that is analyzed and evaluated as opposed to who, what, or how questions providing only a summary or a definition. Similarly, a course of the University of Michigan (2013) takes the position that definitions and questions asking for facts are not critical thinking. Their position is that critical thinking questions require reasoning and should also take implications and consequences into consideration. The Salt Lake Community College (2013) takes a different approach and provides a table of example questions with a hierarchy of rankings similar to Bloom's Higher Order Thinking (see Bloom's levels in Table 1).

On the contrary, Porter (2002), in his text, did not actually provide a definition of critical thinking but opened with an example of a dyad discussion in which each person had a position and they provided reasons to justify their position. A more recent text by Moore and Parker (2011) also opened with an example but provided no precise definition. All of these do establish that critical thinking is dependent upon the bases of the reasoning of the person justifying his or her position. Along the same mode of thinking Tittle (2011) builds a definition based upon Critical Thinking being judicious reasoning. She further stipulates that being judicious means being deliberate and thorough and hence it cannot just be something you have looked up. She argues that it involves comparing and contrasting and noting similarities and differences and also includes examining and evaluating. Critical Thinking requires setting up an argument that can be analyzed with inductive or deductive reasoning when writing and analyzing an argument deductively and inductively when reading (Tittle, 2011). She identifies Richard Paul as the 'guru' of critical thinking. Richard Paul notes, "Most people are not in charge of their ideas and thinking. Most of their ideas have come in to their minds without them having thought about it. They unconsciously pick up what the people around them think. They unconsciously pick up what is on television or in the movies. They unconsciously absorb ideas from the family they were raised in" (Paul \& Elder 2013).

Richard Paul, a noteworthy source for understanding what critical thinking is and what it is not and credited with a root definition for academic study of critical thinking, as from 1987 concurs 
that "Critical thinking is the intellectually disciplined process of actively and skillfully conceptualizing, applying, analyzing, synthesizing, and/or evaluating information..." (Paul \& Elder 2013). Richard Paul is a fellow of the Critical Thinking Community (CTC). The site of the CTC (http://www.criticalthinking.org) provides a more up-to-date definition with, "Critical thinking is that mode of thinking - about any subject, content, or problem - in which the thinker improves the quality of his or her thinking by skillfully analyzing, assessing, and reconstructing it" (Critical Thinking Community, 2013). In their most recent book, Paul and Elder (2013) refer to people being in stages of development of their thinking skills: unreflective, challenged, beginning, and practicing.

The two elements of these descriptions that align with this research study are the concepts of differentiating between deductive and inductive reasoning as highlighted by Tittle (2011) along with the ability to do so being developed over time as argued by Paul and Elder (2013) with their stages of development for thinking skills. The students at The University have not had prior courses in their undergraduate studies which required them to develop critical thinking writing skills. During our research it was revealed that several faculty members did not feel they had received solid training in critical thinking writing. Indeed, one faculty member was using a sample essay which was almost all paraphrased content on the basis that it was less than $30 \%$ quoted content. This essay was largely a report of the thinking of others and contained no reasoning by the student. During discussions with other faculty one faculty member posited that students did not earn the right to question authors' arguments/reasoning/claims until they had earned doctoral degrees. In discussions it was therefore agreed that The University aligns with Paul and Elder's (2013) beginning stage of critical thinking.

In prior courses with The University the both authors' experience was that students predominantly utilized deductive reasoning as a result of their responses coming from what they believed to be valid sources. The result was that the majority of content was quoted, represented a modified quote or was paraphrased which aligns with Bloom's level 1 and 2 thinking (See Table 1). Inductive thinking (Tittle, 2011) aligns with a combination of all of Bloom's levels of thinking building from the deductive elements to the inductive elements. The goal of the case study was to develop a process whereby students would be challenged, trained, and graded based upon increasing the percentage of inductive reasoning in their initial discussion submittals. Recognizing the student's habit of reporting, it was determined that to achieve the goal it would be important to avoid 'who, what, when, where' questions that would tend to be answered by reporting sources that gave specific answers to those questions. The authors determined that questions that called for comparative analysis of the students' experience with the text and research along with training would be more likely to achieve inductive reasoning.

\section{Facilitated Discussions}

The University Online Campus is based upon a facilitative learning model in which the faculty is responsible for stimulating students to increase their learning through critical thinking discussions (Gorsky \& Blau, 2009; Winsted, 2010). The DQ instructions typically included a length range in words rather than paragraphs and did not reiterate or emphasize the requirement to support responses with citations and references. However, being specific in the instructions has been supported in prior studies. Andresen's (2009) review of prior literature reports Guldberg and Pilkington's 2007 findings that "simply forming an asynchronous discussion forum, providing the technology and a question or topic of discussion is not enough to ensure success in an asynchronous discussion." Other research has shown that not all courses are appropriate for the same type of discussions. According to Andresen (2009), at least two studies found that problem-based courses could have DQs related to ideas and concepts and not for actual problem solving. This correlates to the concept that DQs need to have 'no right answer.' 
In some courses students are learning new concepts at the 'how' and 'what' level. In those cases it is the faculty member's goal to have the students find information that is new to them and report what they have found or how something is done. It is important to establish that these are reports rather than critical thinking DQs and correlate them to course objectives that do not ask for synthesis or analysis. Some courses are especially suited to the use of case studies with DQs which require critically thinking about the case. Because there are different 'types' of DQs, the development of each course's options for DQs and the process for DQ selection each week must consciously include the establishing and balancing of the required effort for the DQ type while increasing the percentage of original thinking in critical thinking DQs.

In the light of prior research regarding the benefits of online discussion, Dennen and Wieland (2008) posited that task type would significantly impact the levels of interaction and results. In prior research Dennen and Wieland (2008) found that "when students were asked to discuss topics clearly related to assessments or that encouraged them to share their own experiences they were more likely to contribute than when asked to participate in more generic discussion tasks with unspecified outcomes" (p. 110). In their study Wolff and Dosdall (2010) used discussion questions which were "intended to be provocative and no 'correct' answers were assumed to exist" ( p. 57). This differentiation in typing may have significantly contributed to their results demonstrating that such questions and their resulting participation do have a significant impact on learning outcomes. As a result, it is important to have course DQ development processes which include conscious selection of DQ type. It is critically important to have discussion questions which are related to the course readings (Andresen, 2009; Wolff \& Dosdall, 2010)

Gilbert and Dabbach (as cited in Bradley, Thom, Hayes, \& Hay, 2008) categorized discussion questions by the type of instruction provided which results in the ranking in Bloom's order for the response (See Table 1). In essence, if a student is asked 'how' to do something. an appropriate response from the student is to find a reputable source that says 'how to' and submit his or her answer with very little original content. This 'how' response was ranked as a Bloom's level 1 out of 6 if it is a quote (or modified quote) of the course readings or a level 2 out of 6 if it is a personal interpretation of an article in the student's own words (paraphrase; requires citation). We did code quote/modified quote as level 1 and paraphrases as level 2.

In alignment with The Universities policy that critical thinking essays be a maximum of $30 \%$ quoted material, our goal was to achieve less than $30 \%$ quoted or paraphrased content. We did want to have quoted and/or paraphrased content as support for the students' thinking so any lower goal would not have accurately reflected the balanced writing we sought to achieve. While they included assessing whether the essay was on or off-topic, our goal was to simply examine the extent to which the content was unoriginal (quote, modified quote, or paraphrase) or original (personal experience or critical thinking in synthesis or analysis). Our resulting table is Table 1.

\begin{tabular}{|l|l|l|l|}
\hline \multicolumn{4}{|c|}{ Table 1: Coding Scheme } \\
\hline Code & Description & $\begin{array}{l}\text { Bloom's } \\
\text { Level }\end{array}$ & Gilbert and Dabbach \\
\hline 1 & Exact/Modified Quote & 1 & 1 \\
\hline 2 & Paraphrase & 2 & 2 \\
\hline 3 & Prior Knowledge & 2 & 3 \\
\hline 4 & Experience & 3 & 4 \\
\hline 5 & Analysis & 4 & $5 \& 6$ \\
\hline 6 & Synthesis & 5,6 & $5 \& 6$ \\
\hline
\end{tabular}


Based on the gaps in the literature identified in the literature review section and the online campus of the University of Liverpool's need to increase the Bloom's higher order of thinking for the online discussions of the modules that it offers, the researchers hypothesized that:

$\mathrm{H}_{1}$ : Using discussion questions based upon Bloom's higher order thinking to achieve the weekly objective would increase the percentage of critical thinking in the original response essay.

$\mathrm{H}_{2}$ : Providing critical writing training within the course in announcements and rubrics would increase the percentage of critical thinking in the original response essay.

\section{Research Methodology}

The research was authorized to focus upon a course which was based upon four (4) weeks of Financial Management studies and four (4) weeks of Operations Management studies for Information Systems Management Masters students in a comparative analysis of an existing (original) section and a pilot section. Before the guidelines were developed and implemented, data was collected from the DQs submissions for the selected existing course for weeks 2, 4, and 7 in order to create an 'as is' state content analysis (See Table 2). Content analysis was performed on the DQ original responses. Based upon the experience of the authors in discussions with other experienced faculty, discussion questions were developed which both authors' believed would require a significant percentage of the content to be inductive reasoning in essay format. Because students needed training in essay writing and comparative analysis, the authors collaborated with other experienced faculty of The University to develop writing training, rubrics, and feedback that encouraged comparative analysis essays. This was initiated with informal discussions prior to the research project and completed in three review sessions prior to the pilot section of the course.

\section{Comparative Case Study}

A case study methodology was chosen to emphasize and explore factors, which may lead to directions for the answers to the research question (Benbasat, Goldstein, \& Mead, 1987). Case study based research is an exploratory research technique that investigates a contemporary phenomenon within its real-life context (Yin 1994). Soy (1996) proposed a number of steps that can be used to successfully conduct the case study research. These steps include the definition of the research objective, the selection of the case to be studied, the determination of the methods for data gathering, and the case study analysis techniques. Thereafter, the case study data can be collected and analyzed, and the findings can be summarized in a report (Soy 1996).

As mentioned in the introduction section of this article, the case selected was a course for Information Systems Management majors (ISM masters students) within an online campus affiliated with a United Kingdom university (the University). The course topic was split between 4 weeks for each topic. The first four weeks focused on Accounting/Finance and the next four weeks focused on Operations Management. Online ISM masters students at the University are typically mid-career professionals, generally in their $30 \mathrm{~s}$, in the information technology fields with students from all over the world but a higher concentration of African continent students. The classes are predominantly male, but with some females in all sections. While the students will have had some budgeting experience in the management of projects, they typically consider the course topics to be unrelated to their careers.

The University provides an online classroom with the same course materials for every section of the course each term. In this case the same course materials were provided for both the original section and the pilot section. The original section selected was chosen because the faculty person teaching the section made no changes to the course. The DQs and rubrics were used as provided for the course. In addition, it also had a female faculty. The pilot course had the same materials 
provided. The difference was that the DQs were changed to questions that were posited to increase the percentage of level 4 through 6 that require from the student to express experience, analysis, and synthesis, as shown in Table 1. In addition, during the first four weeks of the course, training was provided in writing skills, and revised rubrics and feedback were used that emphasized the importance of using an increased percentage of original content from the students' own experience and demonstrating critical thinking in the analysis and synthesis.

The case study focused on the lived experience of students in initial discussion question submittals for weeks 2, 4, and 7 in a comparative analysis of a section using the original discussion questions and course materials and a pilot section using the revised discussion questions, writing trainings, rubrics, and feedback. The weeks were selected with specific intent. Week 1 was not selected because students would not have had sufficient time to adjust to the new course and faculty nor would they have had any feedback yet. Week 2 performance demonstrates which students adjust quickly and/or may have had prior experience in critical thinking essays. By week 4 students in the pilot section have had 4 weeks with the revised types of questions, expectations set in trainings, rubrics, and feedback. It is posited that those who will quickly adapt or have prior experience will have adapted by week 4 . Week 7 demonstrates that some of those students who had not yet adapted by week 4 would adapt over more time, or not adapt at all.

The research study used content analysis as the main methodology to perform the comparative analysis of the DQs. Before the revised course contents were finalized, a section of the Resource Management course was selected to test the original DQs and data was collected and analyzed by using content analysis. Online class discussions were updated by using new designed DQs. After the DQs were updated, a pilot term DQ post submittals for weeks 2, 4, and 7 were analyzed for their DQ type, originality/composition, balance of critical thinking/citations, and experience. A qualitative and quantitative comparative analysis between the essays for weeks 2,4 , and 7 in a section prior to the new DQs was performed. The result of the analysis was used to improve the Guidelines used to prepare DQs, and the improvements were validated by using the Delphi method (Loo, 2002).

Faculty with extensive backgrounds in online teaching and over two years experience with The University who participated in a preliminary webinar and a discussion during an annual faculty conference were invited to participate in reviews of the materials developed for the pilot section (the guidelines). Six faculty representing the Computing, Business and Law programs (the panel) accepted the invitation and participated in each of the Skype and Email sessions.

\section{Discussion Question Development}

The primary researcher has prior experience teaching critical thinking together with course design experience and training with the ADDIE methodology (Lohr, 1998; Van Rooij, 2010; Way, 2012). This model takes a developmental approach to the design of a course which builds each assignment and discussion upon the course objective that the student's submittals demonstrate as being achieved. A review of the format of current DQs revealed that the questions that were in use generally oriented to 'how' or 'what' answers. When a DQ is a 'what' question, it can result in an attempt to produce a conversation ending with a 'correct' answer (Wolff \& Dosdall, 2010). Winsted (2010) suggests that creating a debate environment for the classroom discussions increases student engagement and stimulates critical thinking. Amanda Cooley (2009) also creates a form of a debate for her course. She notes that it is important to have such discussions because "Business students benefit from as much exposure to best communication practices as possible" (p.437). Upon this basis and pre-grant faculty workshop discussions, an initial draft of the guidelines, including a DQ development process, was developed utilizing the ADDIE model. The guidelines were reviewed by the panel who provided suggestions for improvement and samples 
from their courses in a sequence of reviews and improvements. While the panel agreed that courses would benefit from a variety of discussion types - 1) Single concept short DQ essay; 2) Multiple concept longer DQ essay; 3) Case study; and 4) Use of the prior week's hand-in assignment) - the pilot course limited the type of discussion to those that would be close to the original question with the exception of being applicable to the student's career experience and challenging the student to use inductive reasoning.

\section{Writing Quality Development}

The panel agreed that critical thinking essay writing requires composition skills. They noted that it is currently assumed that students are trained in critical thinking essay writing. However an informal review of 210 essays during the 2009/2010 school year indicated that this is not a valid assumption. During the international faculty workshop it was identified that many students come into the program with educational backgrounds that have not included training in writing or critical thinking. The panel concluded that courses that include DQs requiring critical thinking need to include instructions that demonstrate how to write in a style that is primarily critical thinking rather than reporting the ideas of others. It was agreed that DQs should include a requirement to apply the topic to the student's life experience. As Porter (2002) cites Socrates, "The unexamined life is not worth living." Additionally, this focus and self-application is part of the Socratic Method. Including the experiential component also increases the breadth of application. Requiring application can show the class all the variations that apply to their various careers and countries.

During each session members provided suggestions for improvement and feedback. These included the realization that not all students or faculty have prior education in critical thinking writing. The panel also pointed out that some cultures expressly teach to only present ideas of published authors, often without credit, and to not disagree with their faculty but to only restate what has been taught. Most have not been taught the structure of an essay. Business writing is not done in critical thinking essay format but in conclusive paragraphs.

The need for writing tutorials was confirmed as faculty shared that not all students participated in undergraduate programs which required academic research or writing, especially in English grammar. Many students with technical undergraduate degrees participated in programmes which were focused on the technical elements. Faculty who were former students of such programs were also accustomed to reporting rather than critical essay writing.

When a discussion question instruction included 'an essay', it was agreed that it could not be assumed that students knew that an essay is structured with at least three paragraphs or that a paragraph is at least three sentences. It could not be assumed that they knew that all facts, figures, and definitions must come from a source that is cited and that changing a few words did not change a quote to a paraphrase as the student was to write in their own words from notes. It was agreed that providing a writing tutorial once would not be sufficient to develop a habit of academic writing. On the other hand, providing the same writing tutorial in each course would soon be ignored. It was agreed that the guidelines should include samples but that the course author should customize tutorials for each course. The panel reviewed and refined samples of writing trainings to be provided during the first four weeks of each course.

Rubrics and grading provide students an incentive to post timely and high quality discussion essays followed by robust participation (Andresen, 2009). Clear expectations and clear guidelines for grading provide consistency across different sections of the same course. That is not to say that all courses ought to have the same rubric. Rather, the DQ Development Process needs to support the creation of course specific rubrics that align with the DQs which align with the Learn- 
ing Objectives but with the same standards of excellence across all courses. The panel members provided and agreed upon samples for rubrics for each of the agreed upon DQ types.

In the next term, the DQs, trainings, and rubrics were implemented. After the course, content analysis data was collected for weeks 2, 4, and 7. The same content analysis was conducted on the pilot course as had been collected on the prior term in order to measure originality/composition and balance of critical thinking/citations and experience. The summary of the research methodologies used are depicted in Figure 1.

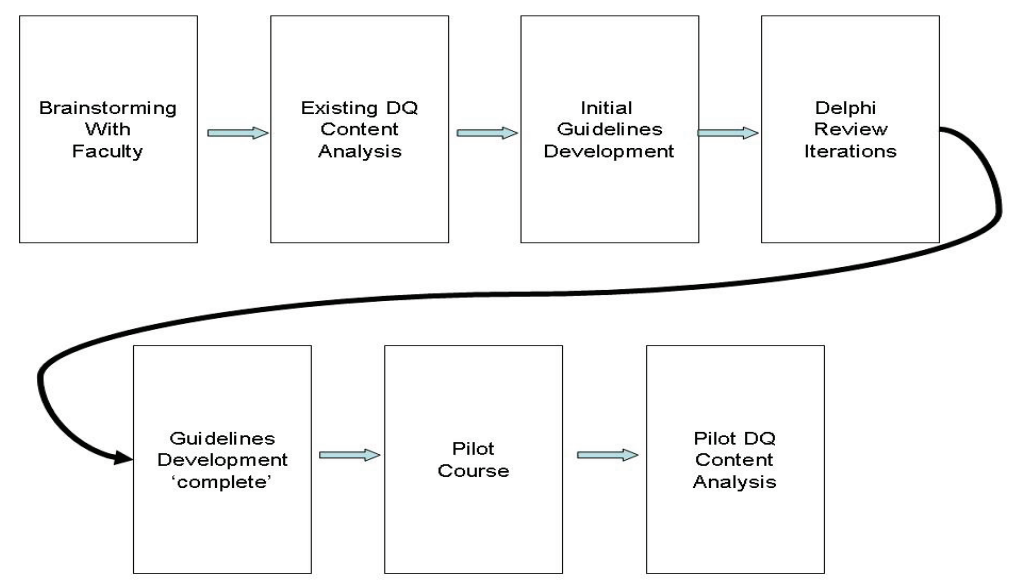

Figure 1. The Research Process Flow

\section{Results and Analysis}

A comparative analysis was performed of the original section of the course and the pilot section of the course. Data was collected for the submissions to the original DQs for the case study analyzed for weeks 2, 4, and 7. Content analysis was performed over the collected data and results summarized in Table 2. For each DQ, the percentage reached at each level was calculated based on the coding technique discussed in the methodology section. We were not concerned with how much of the $30 \%$ was quoted or paraphrased, so the data was captured as levels $1-3$ individually, but analyzed together.

The following discussion questions were used in the original course design:

Week 2 DQ 1: List and describe three accounting and finance features for limited companies? How is accounting and financial reporting regulated in your country? (Chapter 4)

Week 2 DQ 2: What information does a cash flow statement provide? Using a selfcreated example, explain the direct and indirect methods for calculating cash flows from operations activities. (Chapter 5)

Week 4 DQ 1: List and describe the four main investment appraisal methods. Which one is the best method to evaluate a risky investment and why? (Chapter 10)

Week 4 DQ 2: What are the sources of finance for a limited company? Describe the advantages and disadvantages of using debt. (Chapter 12)

Week 7 DQ 1: What roles do operations managers play in addressing the major aspects of service quality?

Week 7 DQ 2: Explain how higher quality can lead to lower costs. 


\begin{tabular}{|l|l|l|l|l|}
\hline \multicolumn{5}{|c|}{ Table 2: Content Analysis for original DQs } \\
\hline Week DQ\# & Level 1-3 & Level 4 & Level 5-6 & Level 4 - 6 \\
\hline Week 2 DQ 1 & $81.89 \%$ & $11.26 \%$ & $6.72 \%$ & $17.98 \%$ \\
\hline Week 2 DQ 2 & $47.99 \%$ & $40.69 \%$ & $11.92 \%$ & $52.61 \%$ \\
\hline Week 4 DQ 1 & $81.81 \%$ & $0.00 \%$ & $18.21 \%$ & $18.21 \%$ \\
\hline Week 4 DQ 2 & $100.00 \%$ & $0.00 \%$ & $0.00 \%$ & $0.00 \%$ \\
\hline Week 7 DQ 1 & $85.76 \%$ & $2.90 \%$ & $11.34 \%$ & $14.24 \%$ \\
\hline Week 7 DQ 2 & $76.51 \%$ & $2.14 \%$ & $21.35 \%$ & $23.49 \%$ \\
\hline
\end{tabular}

New DQs were designed using the proposed guidelines and the pilot course was updated with these new DQs:

Week 2 DQ 1: If you had to select one, which financial ratio category (profitability, efficiency, liquidity, gearing, or investment) do you think is most useful for ISM project managers? Why?

Week 2 DQ 2: Why do international business managers need to be sensitive to account and financial reporting regulations in your country?

Week 4 DQ 1: ROCE measures return on assets after the fact. ARR measures potential returns. Why might a finance department be quizzing the proposal manager (PM) about the ARR? And more importantly, why is it important that the PM give a reasonable ARR?

Week 4 DQ 2: Under what conditions will a company change its payment terms? Why? Limit the breadth of your essay to what you think are the top two reasons in order to have enough depth in your answer.

Week 7 DQ 1: Take a solid position for good or bad: Why is it good or bad to operate an IT support services system (help desk) on a strictly, first-come, first-served basis?

Week 7 DQ 2: Take a solid position: Why and which seasonal period(s) might an IT support services system (help desk) need to be aware of? Limit yourself to one type of seasonal period that applies.

Data was collected for weeks 2, 4, and 7 and analyzed by using content analysis and results are summarized in Table 3. The following example is provided for the Week 4 DQ2. In the original section one student's response was broken down as 529 words total with 529 words being quoted or paraphrased. None of the responses to the original Week 4 DQ2 had any analysis or synthesis. The TurnItIn report found $11 \%$ matched content. This aligns to students potentially following instructions not to use their own experience. In a personal conversation this week in the most recent revised section of the course, when asked why the student was not following the DQ instructions, training, and feedback, a student advised that, "it was clearly mentioned by other Instructor ... purely paraphrase many papers with many citation to write a good academic paper. One instructor told us that we can't post any idea or personal comment without having citation, which is probably why I'm still in the citation/descriptive mode."

In the pilot section one student's response to Week 4 DQ2 was broken down as 602 words with 252 words which were quotes, modified quotes, or paraphrases (level $1-3$ ) and 0 words experiences and 353 words which were analysis and synthesis (level $5-6$ ). The TurnItIn report found 
$0 \%$ matched content. This was the highest percentage of analysis and synthesis amongst the pilot students, but all students did include more analysis and synthesis than the original section.

\begin{tabular}{|l|l|l|l|l|}
\hline \multicolumn{5}{|c|}{ Table 3: Content Analysis for original DQs } \\
\hline Week DQ\# & Level 1-3 & Level 4 & Level 5-6 & Level 4 - 6 \\
\hline Week 2 DQ 1 & $56.26 \%$ & $16.26 \%$ & $27.60 \%$ & $43.86 \%$ \\
\hline Week 2 DQ 2 & $61.41 \%$ & $18.88 \%$ & $19.52 \%$ & $38.39 \%$ \\
\hline Week 4 DQ 1 & $51.80 \%$ & $8.00 \%$ & $39.36 \%$ & $47.36 \%$ \\
\hline Week 4 DQ 2 & $50.24 \%$ & $14.60 \%$ & $35.17 \%$ & $49.77 \%$ \\
\hline Week 7 DQ 1 & $22.97 \%$ & $22.17 \%$ & $43.10 \%$ & $65.27 \%$ \\
\hline Week 7 DQ 2 & $27.81 \%$ & $24.88 \%$ & $29.66 \%$ & $54.54 \%$ \\
\hline
\end{tabular}

The original course DQ served as a baseline for the study. Preliminary results demonstrated that the level of critical thinking significantly improved from week 2 to week 7 according to Figure 2 . For week 2, DQs 1 and 2 scored $6.72 \%$ and $11.92 \%$ respectively for levels 5-6; for the same week after the update with the new DQs was performed, DQs 1 and 2 scored $27.6 \%$ and $19.52 \%$ showing a considerable improvement in terms of critical thinking. For week 4, DQs 1 and 2 originally scored $18.21 \%$ and $0 \%$. For the same week after the update, DQs 1 and 2 scored $39.26 \%$ and $35.17 \%$ showing again a considerable improvement. Week 7 showed also improvement from $11.34 \%$ to $43.10 \%$ for DQ1 and from $21.35 \%$ to 29.66 for DQ2.

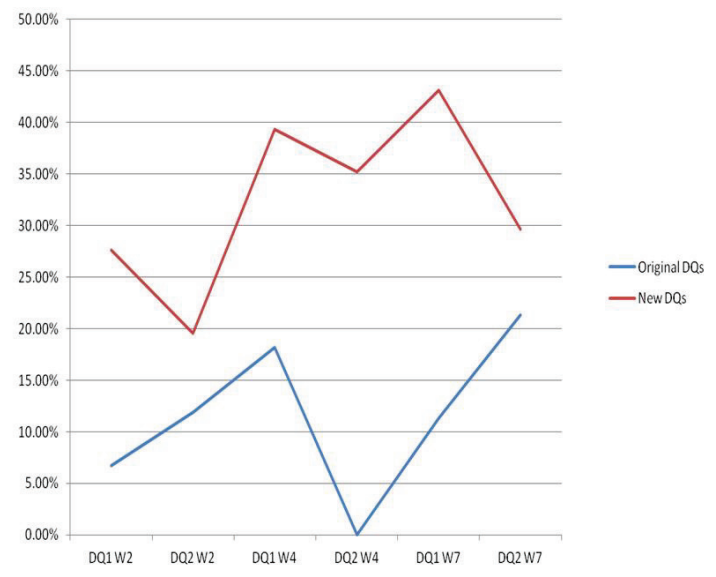

\section{Figure 2. Comparative Analysis of DQ Content}

The mean values of the Bloom's taxonomy levels 5-6 for the original DQs and new DQs were compared to check if there was an improvement in the achievement of learning objectives and critical thinking in online class forum asynchronous. The mean values were tested using the tStudent test, and the t-values were calculated by using the following formula:

\footnotetext{
$t$-value $=($ Mean of post-test - Mean of pre-test $) /$ square root (Variance of post-test / Sample size of post-test +

Variance of pre-test / Sample size of pre-test)
} 
The Alpha level used was 0.05 of one tail test; the sample size is 9 , the degree of freedom $=$ sample size of original DQs + sample size of new DQs $-2=16$. According t-distribution significance table, the critical value is 1.746 for one tail test. As shown in Table 4, as far as the Null Hypothesis is concerned, there is no difference between the original DQs and new DQs sample means for the Bloom's taxonomy levels 5-6.

Table 4. Null Hypothesis of the difference of means

\begin{tabular}{|l|l|l|l|l|l|l|l|}
\hline & Mean & $\begin{array}{l}\text { Standard } \\
\text { Deviation }\end{array}$ & Mean & $\begin{array}{l}\text { Standard } \\
\text { Deviation }\end{array}$ & t-value & p-value & \\
\hline DQ1 Week 2 & $6.72 \%$ & $10.14 \%$ & $27.60 \%$ & $26.57 \%$ & 2.202 & 0.0213 & Reject \\
\hline DQ2 Week 2 & $11.92 \%$ & $11.99 \%$ & $19.52 \%$ & $18.67 \%$ & 1.028 & 0.1596 & Accept \\
\hline DQ1 Week 4 & $18.21 \%$ & $9.20 \%$ & $39.36 \%$ & $23.79 \%$ & 2.488 & 0.0121 & Reject \\
\hline DQ2 Week 4 & $0.00 \%$ & $0.00 \%$ & $35.17 \%$ & $19.47 \%$ & 5.420 & 0 & Reject \\
\hline DQ1 Week 7 & $11.34 \%$ & $17.31 \%$ & $43.10 \%$ & $25.19 \%$ & 3.118 & 0.0033 & Reject \\
\hline DQ2 Week 7 & $21.35 \%$ & $22.21 \%$ & $29.66 \%$ & $25.10 \%$ & 0.744 & 0.2338 & Accept \\
\hline
\end{tabular}

The hypothesis for DQ2 for week 2 and DQ2 for week 7 were accepted, this means that these were the only two questions that did not show a significant difference of the means. The other 4 questions were rejected; this means that their means showed a significant difference that can be attributed to the implementation of the new guidelines.

Using the above methods two DQs did not show enough difference to be statistically significant. The other DQs did demonstrate the effectiveness of the proposed guidelines. It must be noted that the goal was not to have no level 1 through 3 content but to have a balance of content dependent upon the DQ type with all DQs having increased original critical thinking. Further examination of the questions and responses to the two questions with the least variance revealed that although the question asked the student 'why,' the resulting answers were based upon focusing on reporting definitions or words used in the questions and/or reporting what researched articles provided as the reasons.

\section{Conclusion}

The answer to the research question was achieved with the generation of guidelines that are based upon on-going education in critical thinking and writing for both Faculty and Students during the facilitation of courses. The content analysis of the research showed that the guidelines were able to increase the achievement of learning objectives and critical thinking in online class forum asynchronous. It was observed that ongoing content analysis could be used to identify whether any specific DQ was achieving the level of critical thinking intended for that DQ, as may vary by DQ type.

The contribution of the results of this research can benefit the universities, faculty, and students. Students can benefit from being challenged to increase their depth and quality of critical thinking. The ability to question why things happen or if they are true or false are critically important to debate and contribute to the development of executive leadership skills and career advancement into top management positions. Thus the improved discussion activities will enhance the student learning outcomes. 
The course designers and faculty can benefit by having tools to assist them in the development and facilitation of effective discussion activities. The templates for writing training will promote more effective essay writing by students, which stimulates more robust participation. The rubrics for discussion activity grading will aid faculty in consistent grading across all sections.

The universities can benefit by having discussion activities which are designed to meet the course learning objectives. This methodology will support any accreditation or other approval or certification processes. The reputation of the university will be enhanced as a result of graduating students with higher levels and depths of critical thinking and communication skills.

Although the research results are beneficial, there are still challenges that need to be addressed. Further research into why some students do not read and reply and others might read but do not begin to comply might lead to methods to increase the depth of learning and application of critical thinking. Additional research into the impact and advantage of an initial Faculty training, as part of faculty development, and a Student readiness course is recommended.

\section{References}

Andresen, M.A. (2009). Asynchronous discussion forums: Success factors, outcomes, assessments, and limitations. Educational Technology \& Society, 12(1), 249-257.

Benbasat, I., Goldstein, D., \& Mead, M. (1987). The case research strategy in studies of information systems. MIS Quarterly, 4, 368-386.

Bradley, M. E., Thom, L. R., Hayes, J., \& Hay, C. (2008). Ask and you will receive: How question type influences quantity and quality of online discussions. British Journal of Educational Technology, 39(5), 888-900.

Choi, I., Land, S. M., \& Turgeon, A. (2007). Instructor modeling and online question prompts for supporting peer-questioning during online discussion. Journal of Educational Technology Systems, 36(3), 255275.

Cooley, A. H. (2009). "Piggybacking" on business communication through interdisciplinarity: Developing student communication skills in legal environment of business courses. Business Communication Quarterly, 72(4), 431-438.

Critical Thinking Community. (2013). Our concept and definition of critical thinking. Accessed 11 Nov 2013 from http://www.criticalthinking.org/pages/our-concept-and-definition-of-critical-thinking/411

Dennen, V. P., \& Wieland, K. (2008). Does task type impact participation? Interaction levels and learner orientation in online discussion activities. Cognition and Learning, 6, 105-124.

Du, J., Yu, C., \& Olinzock, A. (2011). Enhancing collaborative learning: Impact of "question prompts" design for online discussion. Delta Pi Epsilon Journal, 53(1), 28-41.

Gorsky, P., \& Blau, I. (2009). Online teaching effectiveness: A tale of two instructors. The International Review of Research in Open and Distance Learning, 10(3), 1-27.

Guldberg, K., \& Pilkington, R. (2006). A community of practice approach to the development of nontraditional learners through networked learning. Journal of Computer Assisted Learning, 22(3), 159171.

Land, S. M. (2000). Cognitive requirements for learning with open-ended learning environments. Educational Technology Research and Development, 48(3), 61-78.

Levy, Y., \& Ellis, T. J. (2006). A systems approach to conduct an effective literature review in support of information systems research. Informing Science: International Journal of an Emerging Transdiscipline, 9, 181-212. Retrieved from http://www.inform.nu/Articles/Vo19/V9p181-212Levy99.pdf 
Lohr, L. (1998). Using ADDIE to design a web-based training interface. Paper presented at the Society for Information Technology \& Teacher Education International Conference, Washington, DC, March, 1014, 1998.

Loo, R. (2002). The Delphi method: A powerful tool for strategic management. Policing: An International Journal of Police Strategies and Management, 25(4), 762-769.

Moore, B., \& Parker, R. (2011). Critical thinking (10th ed.). USA: McGraw-Hill, USA. ISBN 10: 0078038286

Paul, R., \& Elder, L. (2013). Critical thinking: Tools for taking charge of your professional and personal life. NJ: Pearson Education. ISBN 10: 0-13-311528-3

Porter, B. F. (2002). Fundamentals of critical thinking: The voice of reason. New York: Oxford University Press.

Salt Lake Community College. (2013). Examples of critical thinking question stems. Retrieved 11 Nov 2013 from http://www.slcc.edu/assessment/docs/CT Appendices/Appendix\%20D\%20$\% 20$ Examples $\% 20$ of $\% 20$ Critical $\% 20$ Thinking $\% 20$ Question $\% 20$ Stems.pdf

Soy, S. (1996). The case study as a research method. Retrieved 15 March 2003 from https://www.ischool.utexas.edu/ ssoy/usesusers/1391d1b.htm

Strang, K. D. (2011). How can discussion forum questions be effective in online MBA courses? CampusWide Information Systems, 28(2), 80-92.

Tittle, P. (2011). Critical thinking: An appeal to reason. (eBook) NY and UK: Routledge. ISBN: 0-20384161-1

University of Dayton. (2013). Questions and critical thinking. Retrieved 11 Nov 2013 from http://academic.udayton.edu/health/syllabi/bioterrorism/syllabus/read03c.htm

University of Michigan. (2013). Critical thinking questions. Retrieved 11 Nov 2013 from http://www.umich.edu/ elements/probsolv/strategy/examplequestions.doc

Van Rooij, S. W. (2010). Project management in instructional design: ADDIE is not enough. British Journal of Educational Technology, 41(5), 852-864. DOI: 10.1111/j.1467-8535.2009.00982.

Ward, D. (2011). Expanding the reference vocabulary: A methodology for applying Bloom's taxonomy to increase instruction in the reference interview. Reference Services Review, 39(1), 167-180. DOI $10.1108 / 00907321111108187$

Way, R. (2012). Instructional design: Using the ADDIE model. Retrieved from http://raleighway.com/addie

Webb, E., Jones, A., Barker, P., \& van Schaik, P. (2004). Using e-learning dialogues in higher education. Innovations in Education and Teaching International, 41(1), 93-103.

Wolff, B. G., \& Dosdall, M. R. (2010). Weighing the risks of excessive participation in asynchronous online discussions against the benefits of robust participation. MERLOT Journal of Online Learning and Teaching, 6(1), 55-61.

Winsted, K. (2010). Marketing debates: In the classroom and online. Marketing Education Review, Spring 2010, 77-82 DOI: 10.7253/MER1052-8008200111

Yin, R. K., (1994). Case study research-design and methods (Vol. 5, 2nd ed.). In applied social research methods series. Newbury Park: Sage. 


\section{Biographies}

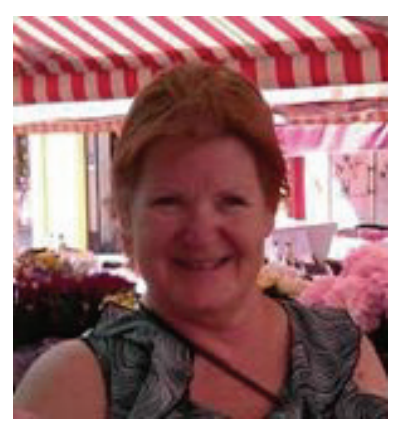

Dr. Conna Condon is an Honorary Lecturer and Outstanding Faculty 2013 for the University of Liverpool Online Programme. She earned her doctorate at Nova SouthEastern University, Ft. Lauderdale, Florida, USA. Her industry background includes being a Director of Contracts which led to a career consulting in information systems management and aerospace process management. Her educational research interests include team dynamics and critical thinking. She serves as a dissertation advisor in the areas of eCommerce and project management. She is the Student Division Chair for the Institute of Behavioral and Applied Management (IBAM).

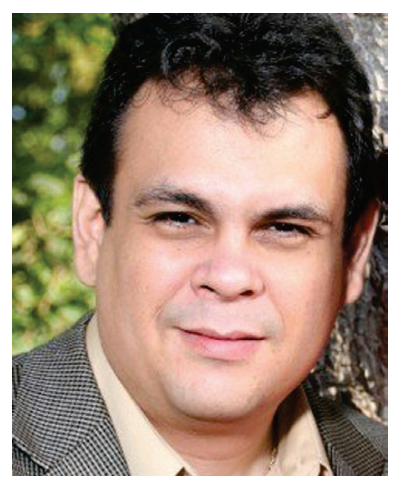

Raul Valverde is a Lecturer of Supply Chain Operations Management and Business Technology Management at the John Molson School of Business at Concordia University in Montreal Canada. He holds a Doctor of Business Administration in Information Systems from the University of Southern Queensland (Australia), a Master of Engineering in Electrical and Computer Engineering from Concordia University (Canada) and a Post MBA in Management Science from McGill University (Canada). He is also a registered professional engineer in Ontario and has several certifications in supply chain Management, information technology and forensics. His research interests include financial systems, supply chain finance, supply chain fraud, supply chain systems, risk management, reengineering and e-business. 